\title{
Animal Models of Dyssynchrony
}

\author{
Marc Strik • Lars B. van Middendorp • Kevin Vernooy
}

Received: 27 October 2011 / Accepted: 17 November 2011 / Published online: 1 December 2011

(C) The Author(s) 2011. This article is published with open access at Springerlink.com

\begin{abstract}
Cardiac resynchronization therapy (CRT) is an important therapy for patients with heart failure and conduction pathology, but the benefits are heterogeneous between patients and approximately a third of patients do not show signs of clinical or echocardiographic response. This calls for a better understanding of the underlying conduction disease and resynchronization. In this review, we discuss to what extent established and novel animal models can help to better understand the pathophysiology of dyssynchrony and the benefits of CRT.
\end{abstract}

Keywords Left bundle branch block · Dyssynchrony . Animal research $\cdot$ Cardiac resynchronization therapy

\section{Introduction}

To maintain normal cardiac pump function, a near synchronous electrical activation sequence of both ventricles is imperative. This synchronous activation applies to multiple anatomic levels: within atria, between atria and ventricles, between ventricles, and especially within the left ventricle (LV). Right-sided pre-excitation, such as during left bundle branch block (LBBB) and right ventricular (RV) pacing,

Electronic supplementary material The online version of this article (doi:10.1007/s12265-011-9336-5) contains supplementary material, which is available to authorized users.

M. Strik $(\bowtie) \cdot$ L. B. van Middendorp

Department of Physiology, Cardiovascular Research Institute Maastricht, Maastricht University,

P.O. Box 616, 6200 MD Maastricht, The Netherlands

e-mail:m.strik@maastrichtuniversity.nl

K. Vernooy

Department of Cardiology, Maastricht University Medical Center, Maastricht, The Netherlands induces dyssynchrony, which instantly decreases cardiac pump function and is a risk factor for development of heart failure [1]. Cardiac resynchronization therapy (CRT) attempts to treat dyssynchrony by simultaneous or sequential stimulation of both ventricles in patients with symptomatic heart failure, LV systolic dysfunction, and increased QRS complex duration. Even though large clinical trials clearly show the efficacy of CRT at the population level, in this heterogeneous group of patients, approximately one third does not show evidence of clinical or echocardiographic response after device implantation [2-4]. In addition, the range of response is highly variable, raising the question whether CRT is optimally performed in every patient or whether each patient can benefit equally from CRT. Therefore, a better understanding concerning the effects of dyssynchrony and resynchronization on cardiac pump function is required. The goal of the present article is to review how animal models of dyssynchrony can help clarify the pathophysiology of dyssynchrony and further improve the treatment of dyssynchrony by CRT.

\section{Animal Models of Dyssynchrony}

Over one century ago, Eppinger and Tothberger discovered large and specific changes in QRS morphology after making a small incision in the left or right surface of the interventricular septum in canine hearts [5]. The first dyssynchronous animal model was established and was in fact a dyssynchrony model by a proximal lesion of the bundle branches. Since then, LBBB has been described in humans but also in monkeys and pigs $[6,7]$. Investigating LBBB in other animals may apply less to the human situation, as there are inter-species differences in anatomy of the left bundle branch. For example, in hearts from ox and sheep, the 
bundles are significantly thicker and their branches extend much more towards the epicardium [8]. In rabbit hearts, the left "bundle" is composed of groups of fine sheets covering the subendocardial tissue [9]. Since the extent of electrical asynchrony in dogs is comparable to humans (where a doubling of QRS duration is seen), the canine heart is considered the most suitable animal model for investigating LBBB. In contrast, RV pacing and LBBB increases QRS duration by only $50 \%$ in pigs [7] and even less in goats (unpublished observations).

For obvious reasons, animal experiments have presented more detailed information than clinical studies, but they suffer from limitations such as the fact that most animal studies are performed in (initially) young and healthy animals and that various preparations have been used, which differ from the clinical and intact human situation. Because an animal model based on intraventricular incisions was not suitable to investigate the hemodynamic effects of LBBB, later research focused on dyssynchrony based on ventricular pacing. In 1925, Wiggers described that artificial stimulation of the canine left ventricle (1) slows down the rise of intraventricular pressure, (2) lengthens the isometric contraction phase, (3) lowers the maximal systolic pressure, and (4) increases the duration of systole [10]. Even though it was clear that dyssynchrony has adverse effects on cardiac pump function, major interest in the pathophysiology of dyssynchrony developed only after these effects were revealed in large groups of patients who underwent permanent RV pacing [8]. Similar to LBBB, RV pacing induces delays in transseptal and intraventricular conduction which explains why the hemodynamic effects of altered ventricular activation during RV pacing and LBBB are comparable. However, there are important differences between the two situations. $\mathrm{RV}$ apex pacing disturbs RV activation since pacing induces slow intramyocardial conduction instead of fast conduction through the Purkinje fibers. Secondly, the site of stimulationinduced breakthrough differs from the site of intrinsic breakthrough. Therefore, LV depolarization through the interventricular septum is also different from that during LBBB.

To investigate the effects of LBBB and CRT, a LBBB model was developed in canine hearts [11-13]. Through the aortic valve, an ablation catheter is positioned against the basal septum. Guided by the local endocardial electrogram derived from the tip of the catheter, the left bundle branch is located as evidenced by a sharp deflection between A-wave and V-wave and subsequently ablated (Fig. 1) [13]. Electrical mapping during dyssynchronous activation is discussed more extensively elsewhere in this edition. In short, in the healthy canine heart electrical activation is very synchronous but ablation of the proximal left bundle branch causes a severe delay in the electrical activation of the LV posterolateral wall (Fig. 2). As shown in Fig. 3, the morphology and duration of the QRS complex change and in agreement to the observations of Wiggers, dyssynchronous contraction causes reduction in ejection time and slows rates of rise and fall of LV and aortic pressure and increases duration of isovolumic contraction and relaxation $[14,15]$. For animated echocardiographic short-axis LV examples of normal conduction and left bundle branch block, see Online Resource 1 and 2.

\section{Electromechanical Delay}

Myocardial contraction does not immediately follow depolarization, and the delay between local electrical activation and shortening, or electro-mechanical delay, was found to be approximately $30 \mathrm{~ms}$ in normal canine hearts [16]. More advanced measurements (MRI tagging) at many sites in asynchronous ventricles showed that timing differences in

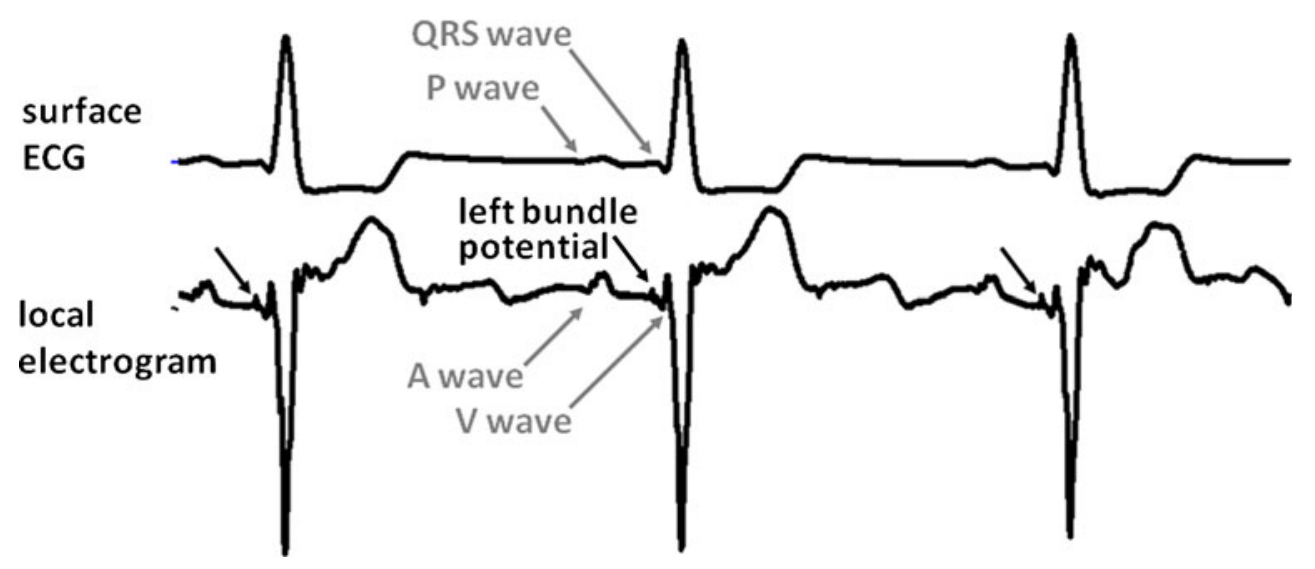

Fig. 1 Creation of left bundle branch through radiofrequency ablation: on the electrogram derived from a standard ablation catheter, introduced through the aortic valve into the LV, the left bundle branch potential is observed as a sharp deflection between the A-wave and
V-wave in the local electrograms (bottom tracing). Subsequently, ablation is started at this location, which results in a proximal LBBB. The top tracing shows a simultaneously recorded surface electrocardiogram 


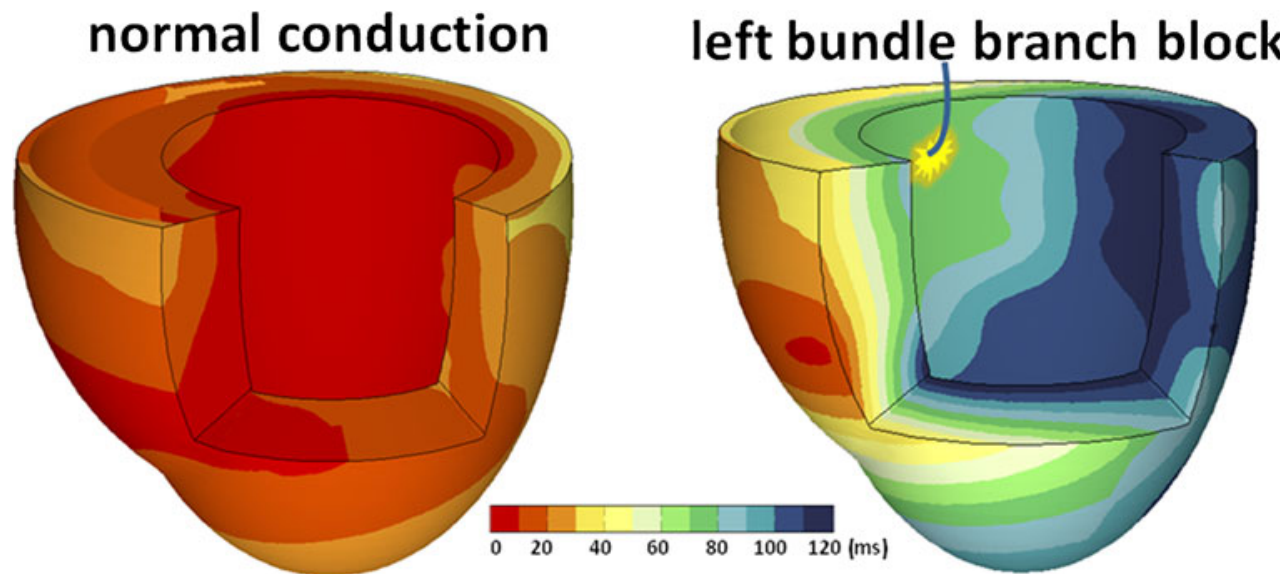

Fig. 2 Typical examples of 3D electrical activation in canine hearts during normal conduction (left panel) and after creation of LBBB (right panel). Plotted activation times were derived from $\approx 110$ epicardial and endocardial contact electrodes and referenced to the

shortening are larger than in electrical activation [17]. This larger mechanical asynchrony is presumably explained completely by its definition: the onset of shortening. Recent studies in canine hearts indicate that when the onset of active force generation rather than the onset of shortening is used to define mechanical activation, electro-mechanical delay is equal throughout the asynchronous heart and directly reflects the timing of electrical activation [18]. This discrepancy between onset of active force generation and onset of shortening is explained by the fact that early-activated regions can start to shorten immediately upon activation, because cavity pressure is low and all other muscle fibers are passive, while this is not valid for late activated regions onset of the Q wave. In the right panel, the ablation catheter is shown with the approximate location of ablation after which a LBBB pattern occurred

(see also the short-axis echocardiography; Online Resource 2). The prolonged electro-mechanical delay in the later activated region could not be explained by increased excitation-contraction coupling time or increased pressure at the time of local depolarization. However, the higher rate of rise of $L V$ pressure $(\mathrm{d} P / \mathrm{d} t)$ that late activated regions have to oppose prolongs the interval when force generation is accelerated to a rate superior to load rise, resulting in delayed onset of shortening [19]. Moreover, the septum contracts against a reduced load resulting in a faster than normal shortening during the isovolumic phase. This phenomenon can be used as an echocardiographic marker for dyssynchrony and is possibly able to predict response to CRT [20]. Additionally, early septal
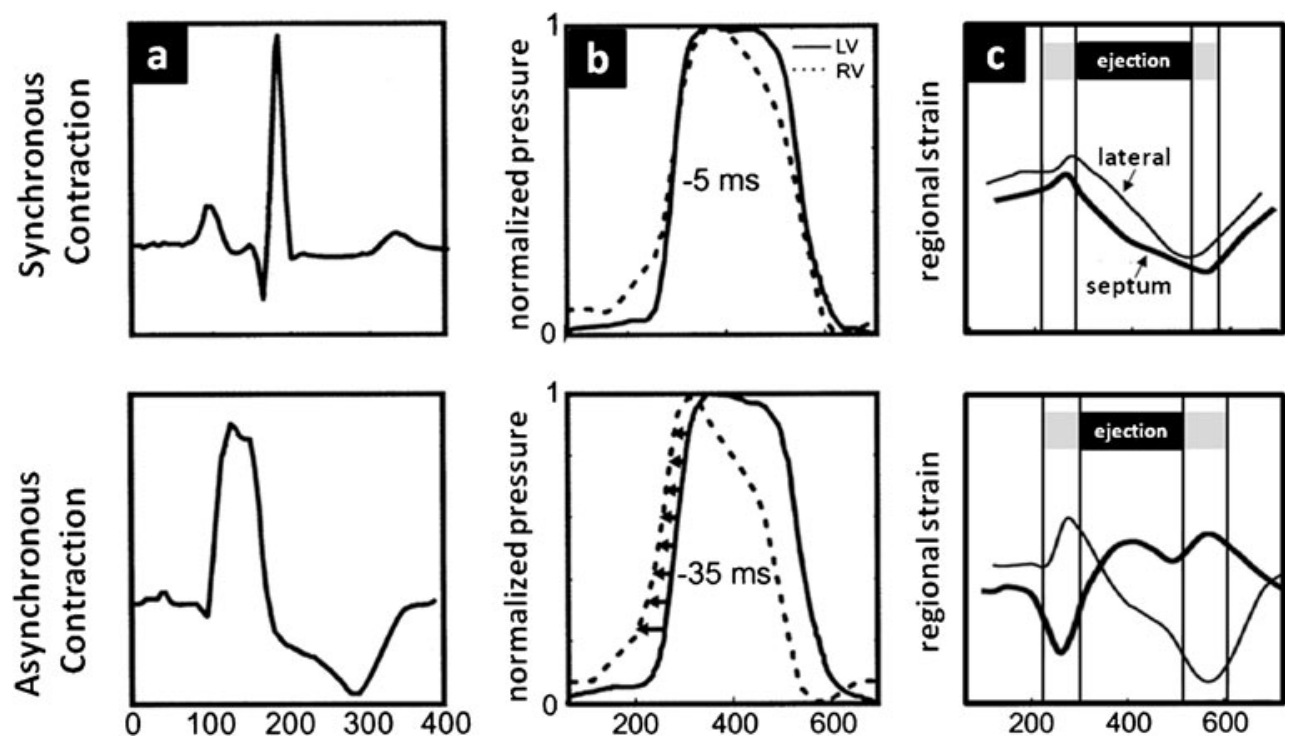

Fig. 3 Effects of synchronous (top) and asynchronous (bottom) ventricular activation. Asynchronous electromechanical activation induces increased QRS duration (a) mechanical interventricular assynchrony (b) and onset of LV shortening (strain) is regionally delayed (negative deflection of curve) (c). Adapted with permission from Verbeek et al. [13] 
contraction pre-stretches the left ventricular free wall and when this region starts to contract after its delayed onset of shortening will stretch the septum again [21]. This combination of delayed onset of shortening, early septal shortening, and reciprocated stretching causes a less effective contraction and reduces the rate in rise of pressure. The early fiber shortening in early-activated regions and pronounced shortening in late activated regions found in canine dyssynchrony models was also found in LBBB patients [19, $22,23]$. Since $\mathrm{LV} d P / \mathrm{d} t$ reflects $\mathrm{LV}$ function and contractility, the magnitude of mechanical dyssynchrony may vary over time in a given patient when there are changes in LV function [19].

\section{Structural Remodeling}

The ventricular wall is capable of adapting to changes in workload by changing the extracellular matrix composition and by hypertrophy of cardiomyocytes. It is not entirely clear which mechanisms are responsible for initiating these changes, but neurohumoral and cardiac load have been ascribed to play an important role. Within the LV wall, an asynchronous electrical activation causes a redistribution of mechanical work, perfusion and oxygen demand [22, 24]. Ventricular pacing results in reductions in regional myocardial perfusion and oxygen consumption near the pacing site. Moreover, the larger mechanical load in late activated regions leads, in the long run, to increased wall thickness in regions opposing the site of pacing, while early-activated wall segments tend to become thinner $[21,22,25]$. The latter is even more the case in canine hearts, which were paced at the $\mathrm{RV}$, while pressure overload was induced by aortic banding. In this model, no added hypertrophy was seen in the lateactivated wall, but a clear inhibition of hypertrophy in the early-activated septum [26]. The generally more pronounced hypertrophy in the pre-stretched regions indicates that the local mechanical load is an important stimulus in this remodeling process [25]. On top of abnormal contraction, premature relaxation in early-activated regions and delayed contraction in others cause abnormal relaxation [8].

\section{Myocardial Perfusion and Metabolism}

To investigate regional myocardial blood flow, the microsphere deposition method can be used, the gold standard for regional blood flow measurements. After injection of radioactive or fluorescent microspheres, deposition is measured and thereby provides information on regional perfusion [27]. During sinus rhythm, blood flow is homogeneous and equally distributed. However, in the dyssynchronous heart, early-activated regions consistently show a reduced myocardial blood flow, while higher flow is observed in late-activated regions $[22,28]$. Closely related to myocardial blood flow is myocardial oxygen consumption $\left(\mathrm{MVO}_{2}\right)$. Not surprisingly, $\mathrm{MVO}_{2}$ shows a similar distribution as myocardial blood flow, where early-activated regions show a reduction in $\mathrm{MVO}_{2}$ and a near normal oxygen consumption is observed in the latest activated regions [28]. Oxygen extraction from the blood is not altered in the different regions and remains stable over a wide physiological range. Therefore, it is speculated that the local changes in workload, due to dyssynchronous contraction, changes the local oxygen demand and thereby local perfusion. In humans, dyssynchrony has usually a silent onset and is often first diagnosed when patients present themselves with other cardiovascular problems. Frequently non-invasive myocardial imaging is performed to diagnose perfusion defects due to coronary artery disease (CAD). However, septal perfusion defects are frequently found in patients with LBBB in the absence of any significant CAD [29, 30]. As argued above, the data from animal studies suggest that this effect in patients is probably due to reduced oxygen demand, caused by the underlying electrical substrate. An alternative hypothesis of the septal underperfusion in dyssynchronous hearts is that perfusion is hampered by the abnormal contraction, which augments intramyocardial pressure and shortens the diastolic period, where coronary perfusion occurs [31-33].

Changes in myocardial blood flow and workload are paralleled by changes in metabolism. In dogs with dyssynchronous hearts, glucose uptake in the septum is markedly reduced in a similar fashion as the redistribution in myocardial blood flow [31]. In patients with dyssynchrony, a relative reduction of glucose uptake in the septum compared to the lateral wall is observed as assessed by fluorodeoxyglucose positron emission tomography imaging. However, the perceived reduction in glucose uptake in the septum may also be due to an increase in absolute glucose uptake in the lateral wall, caused by an increase in work load and higher energy demand in that wall [34].

\section{Cardiac Resynchronization Therapy in Animal Models}

Immediately upon inducing LBBB in the canine hearts, LV $\mathrm{d} P / \mathrm{d} t_{\max }$ decreased by $22 \%$ and adverse effects as described in earlier animal models of pacing induced dyssynchrony are reproduced [35]. Interestingly, biventricular pacing in the LBBB heart immediately causes an almost normalization of the strain pattern (Fig. 4) and increases $\mathrm{LV} \mathrm{d} P / \mathrm{d} t_{\max }$ to $86 \pm 5 \%$ of pre-LBBB followed by a slight further improvement to $89 \pm 5 \%$ of pre-LBBB values after 8 weeks of CRT. Therefore, the data from this animal study indicate that CRT clearly improves cardiac pump function in the LBBB hearts, but does not return it completely to pre-LBBB values. 
Fig. 4 Typical example of myocardial circumferential shortening (\%) tracings in eight regions along the mid-basal LV circumference. Please note the abnormal shortening patterns during LBBB and the normalization during CRT $(L B B B+C R T)$

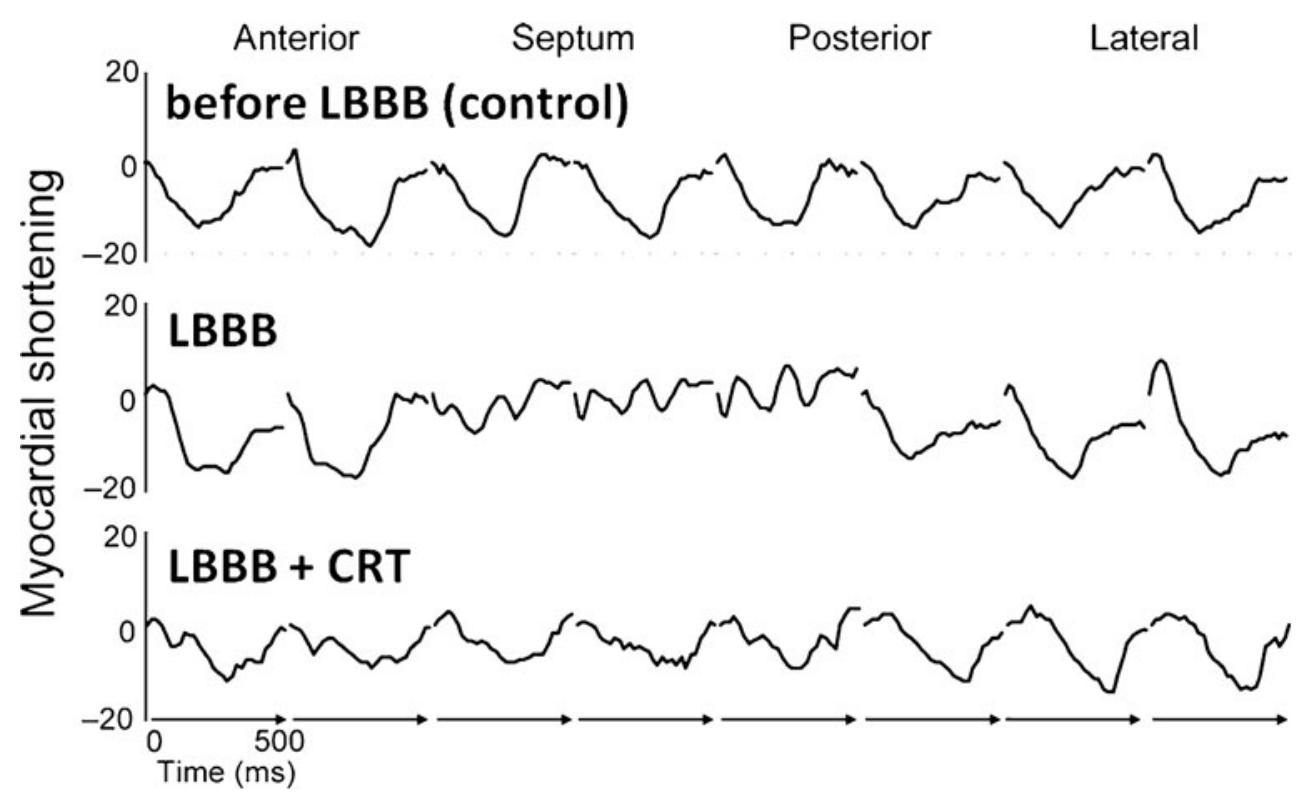

This could be explained by the fact that the physiological sequence of activation and contraction are never completely restored during CRT, remaining less efficient than through the Purkinje system [36]. Asymmetric hypertrophy, as seen during chronic LV pacing, also applies to the situation of LBBB [37]. Eight weeks after creation of LBBB, wall mass of the lateral wall and LV cavity size increased by $\approx 30 \%$, whereas mass of the septum barely changed [37]. After 8 weeks of CRT, LV cavity size and regional differences in hypertrophy normalized to pre-LBBB levels. The observations made in these dog models are readily translatable to the human situation. In patients with LBBB, the effect of asynchronous activation on regional hypertrophy was comparable to that observed in dogs. Nonetheless, the effects of CRT are less pronounced in patients possibly due to the large heterogeneity and confounding factors such as hypertrophy, fibrosis, infarction, and dilatation that are so often present in these patient groups [34, 38].

The aforementioned findings give rise to the notion that dyssynchronous ventricular activation by LBBB on its own is sufficient for CRT to be efficient. The described animal models contain dyssynchronous activation either by ventricular pacing or by proximal ablation of the left bundle branch and, unlike CRT candidates, these models do not suffer from co-morbidities complicating their conduction defect. It is important to understand the effects of additional factors such as LV systolic dysfunction for better selection of CRT candidates and to improve response to treatment. In healthy canine hearts, isolated LBBB induces electrical and mechanical dyssynchrony that eventually will lead to loss of LV pump function and ventricular remodeling. In these hearts, CRT largely reversed global and regional function and structural abnormalities, indicating that LBBB as electrical substrate is sufficient for acute and long-term response to CRT [39]. Recently, multiple clinical trials have indeed shown high CRT efficacy in heart failure patients who were not severely symptomatic (NYHA class I and II) [2, 40-43].

\section{Role of Infarction in CRT}

While, based on these studies, inclusion criteria for CRT may be extended to patients without severe symptomatic heart failure, still a significant number of patients complying with the current guidelines do not respond to CRT. To this regard, most clinical studies show that the number of nonresponders is highest in patients who suffer from ischemic cardiomyopathy (ICM). One possible mechanism is that there is insufficient viable tissue to allow an increase in contractility by CRT. Another possible mechanism lies in modification of the electrical substrate where the extent of resynchronization would be limited as a result of slowconducting or non-conducting regions. This would mean that a good response to CRT in ICM patients not only requires clear conduction disease, but also the capability to properly resynchronize the heart. An important feature in this regard is the site of pacing as pacing in the vicinity of scar tissue is considered to compromise conduction.

To investigate this idea, an animal model was developed where asynchronous activation by proximal left bundle branch ablation was combined with myocardial infarction [44]. Transmural myocardial infarction was created by embolization of the left anterior descending (LAD) or circumflex (LCX) artery using a suspension of polyvinyl alcohol foam particles. Four weeks later, LBBB was induced and another week later measurements on electrical activation 
and hemodynamics were performed. TTC staining showed that all infarctions were transmural with an infarct size of $19.9 \pm 6.0 \%$ (range $14-32 \%$ ) of LV mass (see typical example in Fig. 5) [44]. In LBBB hearts with myocardial infarction, pacing remote from the infarcted regions resulted in a similar CRT response as in non-infarcted canine LBBB hearts. Achieving the maximal benefit in infarcted dyssynchronous hearts, however, required accurate positioning of the LV pacing lead and more precise timing of LV stimulation. In infarcted hearts, the optimal pacing site did not coincide with the region of latest activation but rather a region distant from the infarction and more basal or apical than the preferred pacing site in non-infarcted hearts. The optimal LV pacing position in infarcted dyssynchronous hearts appears to be determined by the fastest pathway of activation wavefront from LV and RV electrodes. This study [44] indicated that in hearts with LAD occlusion, the infarction is located apically and basal pacing allows the activation wavefront to bypass the infarcted area. In contrast, the midlateral position is best in case of LCX infarctions since the activation wavefront can easily propagate over the lateral wall and apex. The preclinical data indicate that it is important to know the location of the infarction but in many CRT candidates, this is not known since scar imaging before device implantation is not regularly performed. Even if scar imaging is not feasible, acute hemodynamic or electrocardiographic testing during pacemaker implantation could help to optimize CRT response in patients with underlying ischemic disease.

\section{Role of Dilation on Benefit of (Endocardial) CRT}

Besides ventricular conduction delay and possibly myocardial infarction, many CRT candidates suffer from dilated cardiomyopathy. Even though dyssynchrony alone is

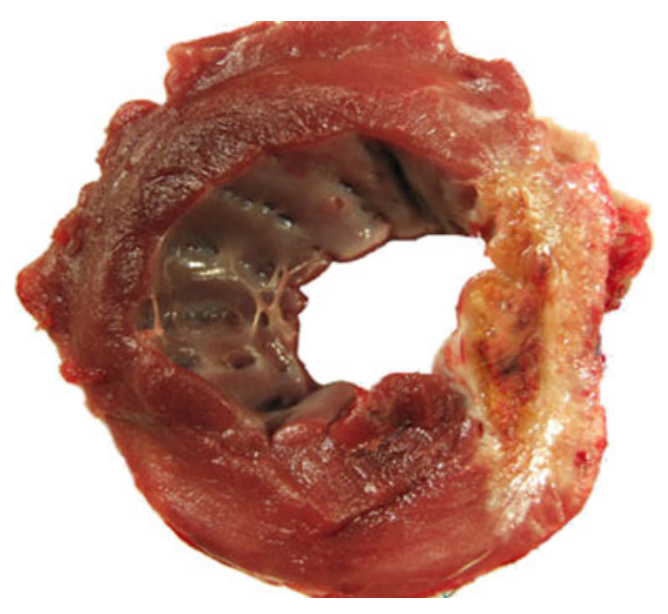

Fig. 5 Short-axis slice at the mid-level of LV demonstrating transmural myocardial infarction of the canine LV lateral wall in the LBBB + infarction model (for details see text) sufficient for CRT to be successful, inducing heart failure in addition to electrical asynchrony can be essential to test certain hypotheses. For example, it was found that in canine hearts with isolated LBBB, endocardial LV pacing during CRT consistently improved systolic LV pump function, reduced electrical asynchrony, and decreased dispersion of repolarization, as compared to epicardial LV pacing at the same site [45]. Three possible mechanisms explaining the more rapid electrical activation during endocardial CRT in this model were proposed: (1) shorter path length of conduction, (2) faster endocardial than epicardial conduction as well as (3) faster conduction from endocardium to epicardium than vice versa. While all three factors may contribute in the setting of LBBB in otherwise healthy canine hearts, ventricular dilatation and wall thinning would reduce the difference in conduction pathlength between endocardium and epicardium, potentially reducing the advantages of endocardial CRT in patients with dilated cardiomyopathy. Better understanding of the various factors determining the benefits of endocardial CRT in animal models with compromised hearts can also be used to propose explanations to ambivalent results reported from the few small clinical studies on endocardial CRT [4648]. For this purpose, we performed a study to investigate the efficacy of endocardial CRT in canine LBBB hearts combined with dilated cardiomyopathy [49]. The results were compared with endocardial CRT in dogs with acute LBBB and in dogs with chronic LBBB and infarction (model as described above). To obtain dilated cardiomyopathy, the apex of the right ventricle was paced at a rate of 220 beats per minute for 4 weeks, as described earlier by other groups [50, 51].

As compared to the acute LBBB group, LV function was depressed in the myocardial infarction group as indicated by decreased stroke work and elevated LV and RV end-diastolic pressures. Echocardiographically, LV end-diastolic diameter remained constant while wall thickness increased. The ratio of LV end-diastolic radius with wall thickness (outer) to LV end-diastolic radius (inner) signifies the type of remodeling, and this ratio was higher in the infarcted dyssynchronous hearts as compared with the acute LBBB hearts (1.88 versus 1.61 , respectively) indicating hypertrophic remodeling. In the failing LBBB group, 4 weeks of rapid pacing induced an increase in LV end-diastolic diameter and a decrease in LV wall thickness. In this model, the ratio of outer LV radius and inner LV radius decreased to 1.36 , reflecting dilatation, which was accompanied by severe systolic dysfunction as evidenced by an LV ejection fraction of $\approx 15 \%$ in combination with $\approx 50 \%$ reduction of $\mathrm{LV} \mathrm{d} P / \mathrm{d} t_{\max }$ and elevation of LV EDP. The differences in pathlength between various dyssynchrony models indeed influenced the effect of (conventional) epicardial or endocardial CRT on electrical resynchronization (as determined by LV electrical mapping). As depicted in Fig. 6, the added benefit of endocardial over 
Fig. 6 Percent change in LV electrical asynchrony during epicardial versus endocardial CRT as a function of the ratio of outer $\mathrm{LV}$ radius to inner $\mathrm{LV}$ radius in the three experimental groups. $P$ values signify a statistical significant difference in ENDO-EPI CRT between groups

\section{outer $L V$ radius / inner $L V$ radius}

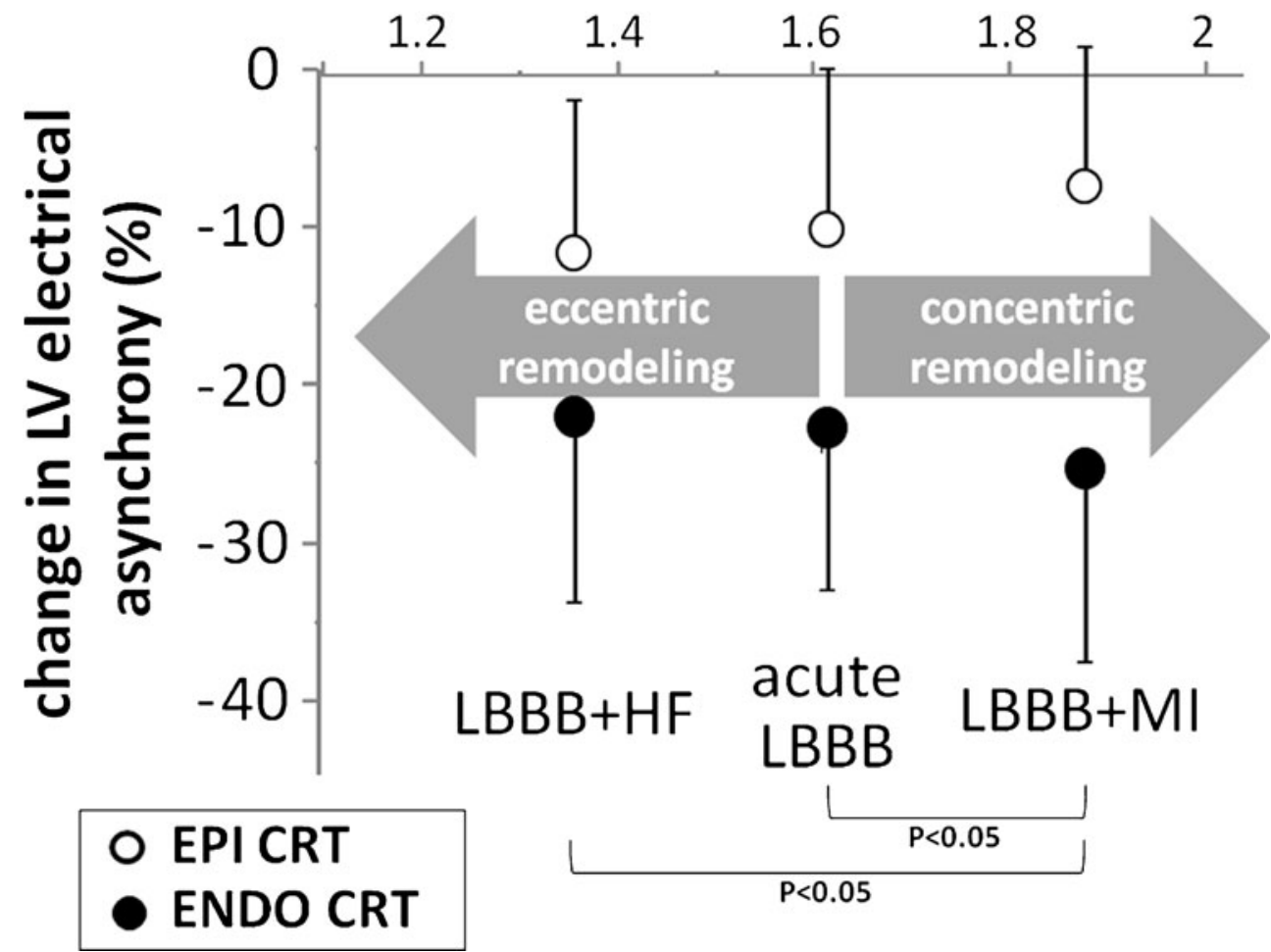

epicardial CRT on electrical resynchronization was greater in hyperthropic than dilated hearts. It was interesting to observe that despite these differences between the three models, CRT resulted in a similar absolute increase in LV $\mathrm{d} P / \mathrm{d} t_{\max } \quad \approx 150 \quad \mathrm{mmHg} / \mathrm{s}$ with epicardial CRT and $\approx 250 \mathrm{mmHg} / \mathrm{s}$ with endocardial CRT). Because baseline $\mathrm{LV} \mathrm{d} P / \mathrm{d} t_{\max }$ was considerably lower in the failing LBBB group, this translated to higher relative increases in $\mathrm{LV} \mathrm{d} P /$ $\mathrm{d} t_{\max }$ during CRT, relative increases that are similar to those found in patients [52]. Therefore, the extent of additional electrical resynchronization by endocardial CRT is dependent on cardiac remodeling but the functional response is not, which could be related to higher subendocardial conduction velocities, faster transmural depolarization, and a shorter pathlength towards the various wall regions. These data further emphasize the benefits of endocardial LV stimulation in CRT patients.

Pacing-induced tachycardia results in severe LV dilatation and decreases LV systolic function to levels similar to those found in heart failure patients. However, evaluating chronic effects of CRT in this model is only possible when tachycardia is maintained during resynchronization as the
Fig. 7 Examples of echocardiography, fluoroscopy, and cardiac MRI in canine hearts before and after creation of mitral regurgitation. The cardiac MRI was performed 5 months after creating mitral regurgitation. Arrows point to the regurgitative blood flow into the left atrium

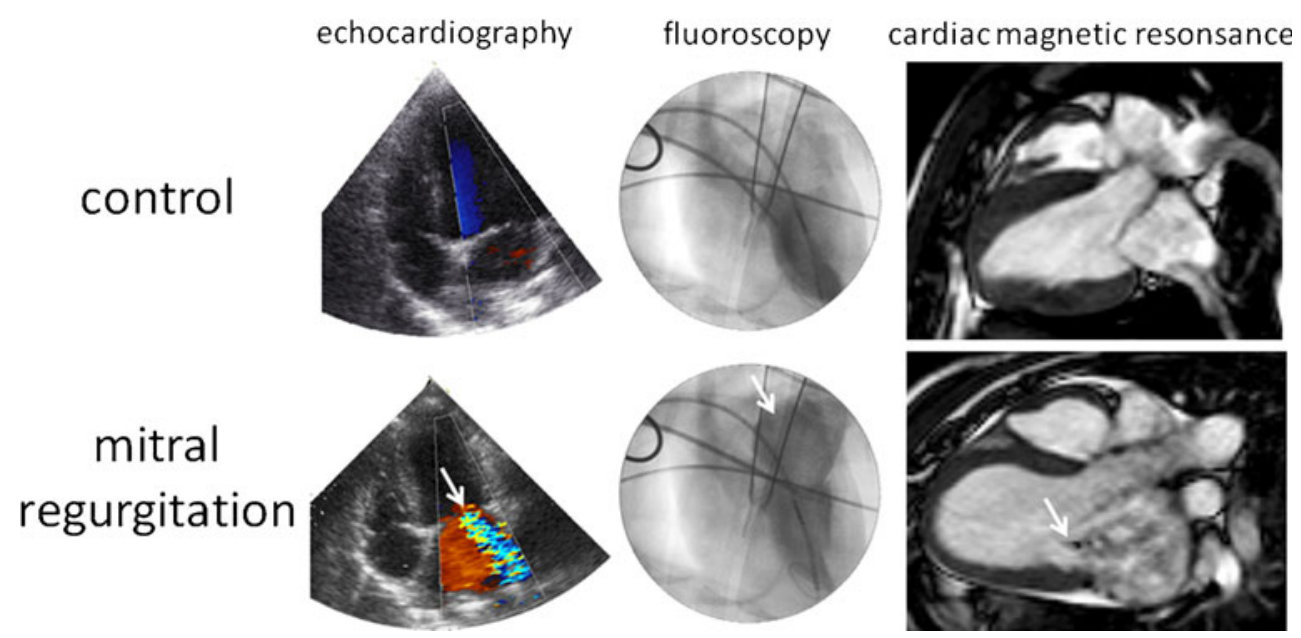


Fig. 8 Bi-weekly echocardiographic follow-up of left ventricular internal diameters of a dog with mitral regurgitation at week -4 . At day 0 , the left bundle branch is ablated. Note the steep increase in end-diastolic and end-systolic internal diameter of the left ventricle after superimposing LBBB upon mitral regurgitation

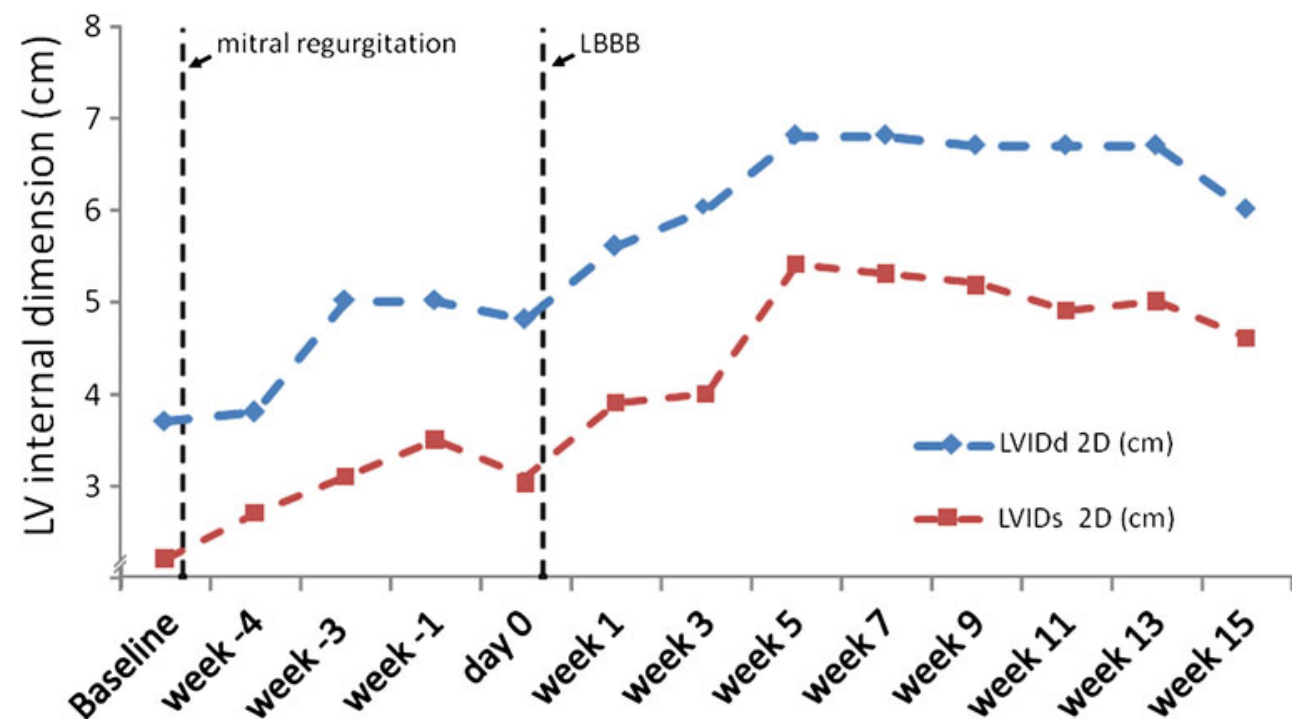

heart would recover independently from therapy. This model has been used to explore genetic alterations induced by dyssynchrony and the capability of CRT (at the same high rate) to restore these alterations [53]. This model provided some interesting data, showing that even though heart rate remained high and hemodynamics hardly improved, electrical resynchronization and mechanical recoordination resulted in extensive cellular and molecular recovery $[54,55]$.

To investigate chronic effects of CRT under physiological heart rates in LBBB and dilated cardiomyopathy, an alternative heart failure model is necessary. Therefore, we have recently commenced the development of a chronic model of heart failure and dyssynchrony in our laboratory by inducing LBBB and mitral regurgitation in canine hearts. The model is based on a known canine mitral regurgitation model in absence of LBBB which was used to investigate atrial fibrillation [56]. Mitral regurgitation was induced using a customized electrophysiology catheter with a hook at the distal tip which was introduced into the left ventricle via the aortic valve. After grasping one or more chorda(e), the hook was withdrawn into a sheet and cauterized to partially obliterate the mitral suspension. This process was repeated until echocardiographic and fluoroscopic evaluation indicated severe mitral regurgitation. Figure 7 shows typical examples of mitral regurgitation on echocardiography, fluoroscopy, and cardiac MRI in canine hearts. For animated examples of cardiac MRI and long-axis echocardiography during one cardiac cycle in a dog with mitral regurgitation, see Online Resource 3 and 4, respectively. One month after the procedure, LBBB was induced by radiofrequency ablation of the left bundle branch. Upon creation of mitral regurgitation, heart rate and LV end-diastolic pressure increased, accompanied by a modest decrease in maximal LV pressure. LV contractility decreased more gradually and after 5 months (including creation of LBBB after 1 month) ultimately decreased to $\approx 57 \%$ of baseline. Clearly left atrial dilatation and pericardial fluid are seen on the cardiac MRI, indicating heart failure. Signs and symptoms of heart failure were also clinically present in the dogs. Meanwhile, LV end-diastolic pressure doubled compared to baseline values and peak systolic pressure decreased to $\approx 83 \%$ of baseline (preliminary data). Figure 8 shows an example of left ventricular dilatation over time in a dog with mitral regurgitation and LBBB. Note the rather steep increase in the first weeks after

Table 1 Canine models of dyssynchrony and associated left ventricular changes in hypertrophy, dilatation, $\mathrm{EF}$, and $\mathrm{d} P / \mathrm{d} t_{\max }$

\begin{tabular}{|c|c|c|c|c|c|}
\hline & Heart rate & Wall thickening & Dilatation & Ejection fraction & $\mathrm{LV} \mathrm{d} P / \mathrm{d} t_{\max }$ \\
\hline LV pacing $[25,57]$ & $=$ & Septal wall & $=/+$ & $=/-$ & $=/-$ \\
\hline LBBB/RV pacing $[26,37]$ & $=$ & Lateral wall & + & - & - \\
\hline added AoS [58] & $=$ & ++ & $=$ & + & + \\
\hline added MI [44, 59] & $=$ & + & + & - & - \\
\hline added MR $[35,60]$ & $=/+$ & - & ++ & $+^{\mathrm{a}}$ & - \\
\hline added atrial tachypacing [53] & ++ & -- & ++ & -- & -- \\
\hline
\end{tabular}

$\angle B B B$ left bundle branch block, $A o S$ aortic stenosis, $M I$ myocardial infarction, $M R$ mitral regurgitation

${ }^{\text {a }}$ Gross EF, including backflow towards the left atrium 
superimposing LBBB upon mitral regurgitation. We expect that this model will be useful to compare effects of isolated dyssynchrony with dyssynchrony complicated by heart failure. Of particular interest are biomarkers sensitive to dyssynchrony and regional differences in wall structure and protein synthesis. As delineated in an overview of discussed canine models of dyssynchrony and their effects on left ventricular characteristics (Table 1), we believe that this novel dyssynchrony model is the animal model which resembles the pathophysiology of CRT patients the closest, especially since mitral regurgitation is also an important component of the dyssynchronous heart.

\section{Conclusion}

Animal models are of great importance in understanding the events and consequences of dyssynchrony and resynchronization. Depending on the hypothesis to be tested, multiple well-established and novel animal models of dyssynchrony exist. Detailed animal experiments demonstrate that ventricular dyssynchrony is a complex disease, which can and needs to be treated in a better way than it is often performed today.

Acknowledgments This research was performed within the framework of CTMM, the Center for Translational Molecular Medicine (www.ctmm.nl), project COHFAR (grant 01C-203), and supported by the Dutch Heart Foundation.

Open Access This article is distributed under the terms of the Creative Commons Attribution Noncommercial License which permits any noncommercial use, distribution, and reproduction in any medium, provided the original author(s) and source are credited.

\section{References}

1. Sweeney, M. O., \& Prinzen, F. W. (2006). A new paradigm for physiologic ventricular pacing. Journal of the American College of Cardiology, 47(2), 282-288. doi:10.1016/j.jacc.2005.09.029.

2. Abraham, W. T., Young, J. B., Leon, A. R., Adler, S., Bank, A. J., Hall, S. A., Lieberman, R., Liem, L. B., O'Connell, J. B., Schroeder, J. S., \& Wheelan, K. R. (2004). Effects of cardiac resynchronization on disease progression in patients with left ventricular systolic dysfunction, an indication for an implantable cardioverter-defibrillator, and mildly symptomatic chronic heart failure. Circulation, 110(18), 2864-2868. doi:10.1161/01.CIR.0000146336.92331.D1.

3. Cleland, J. G., Daubert, J. C., Erdmann, E., Freemantle, N., Gras, D., Kappenberger, L., \& Tavazzi, L. (2005). The effect of cardiac resynchronization on morbidity and mortality in heart failure. The New England Journal of Medicine, 352(15), 1539-1549. doi:10.1056/NEJMoa050496.

4. Bristow, M. R., Saxon, L. A., Boehmer, J., Krueger, S., Kass, D. A., De Marco, T., Carson, P., DiCarlo, L., DeMets, D., White, B. G., DeVries, D. W., \& Feldman, A. M. (2004). Cardiac-resynchronization therapy with or without an implantable defibrillator in advanced chronic heart failure. The New England Journal of Medicine, 350(21), 2140-2150. doi:10.1056/NEJMoa032423.
5. Eppinger, H., \& Rothberger, J. (1910). Ueber die Folgen der Durchschneidung der Tawaraschen Schenkel des Reizleitungssystems. Zeitschrift fur Klinische Medizin, 70, 1.

6. Roberts, G. H., Crawford, J. H., \& Abramson, D. I. (1935). Experimental bundle branch block in the monkey. The Journal of Clinical Investigation, 14(6), 867-870. doi:10.1172/JCI100736.

7. Marrouche, N. F., Pavia, S. V., Zhuang, S., Kim, Y. J., Tabata, T., Wallick, D., Saad, E., Abdul-Karim, A., Schweikert, R., Saliba, W., Tchou, P., \& Natale, A. (2002). Nonexcitatory stimulus delivery improves left ventricular function in hearts with left bundle branch block. Journal of Cardiovascular Electrophysiology, 13(7), 691-695.

8. Prinzen, F. W., \& Peschar, M. (2002). Relation between the pacing induced sequence of activation and left ventricular pump function in animals. Pacing and Clinical Electrophysiology, 25(4 Pt 1), 484-498.

9. Bojsen-Moller, F., \& Tranum-Jensen, J. (1972). Rabbit heart nodal tissue, sinuatrial ring bundle and atrioventricular connexions indentified as a neuromuscular system. Journal of Anatomy, 112 (Pt 3), 367-382.

10. Wiggers, C. J. (1925). The muscular reactions of the mammalian ventricles to artificial surface stimuli. American Journal of Physiology-Legacy Content, 73(2), 346-378.

11. Verbeek, X. A., Vernooy, K., Peschar, M., Van Der Nagel, T., Van Hunnik, A., \& Prinzen, F. W. (2002). Quantification of interventricular asynchrony during LBBB and ventricular pacing. American Journal of Physiology-Heart and Circulatory Physiology, 283(4), H1370-H1378. doi:10.1152/ajpheart.00051.2002.

12. Liu, L., Tockman, B., Girouard, S., Pastore, J., Walcott, G., KenKnight, B., \& Spinelli, J. (2002). Left ventricular resynchronization therapy in a canine model of left bundle branch block. American Journal of Physiology-Heart and Circulatory Physiology, 282(6), H2238H2244. doi:10.1152/ajpheart.00684.2001.

13. Verbeek, X. A., Vernooy, K., Peschar, M., Cornelussen, R. N., \& Prinzen, F. W. (2003). Intra-ventricular resynchronization for optimal left ventricular function during pacing in experimental left bundle branch block. Journal of the American College of Cardiology, 42(3), 558-567.

14. Prinzen, F. W., Van Oosterhout, M. F., Vanagt, W. Y., Storm, C., \& Reneman, R. S. (1998). Optimization of ventricular function by improving the activation sequence during ventricular pacing. Pacing and Clinical Electrophysiology, 21(11 Pt 2), 2256-2260.

15. Zile, M. R., Blaustein, A. S., Shimizu, G., \& Gaasch, W. H. (1987). Right ventricular pacing reduces the rate of left ventricular relaxation and filling. Journal of the American College of Cardiology, 10(3), 702-709.

16. Prinzen, F. W., Augustijn, C. H., Allessie, M. A., Arts, T., Delhaas, T., \& Reneman, R. S. (1992). The time sequence of electrical and mechanical activation during spontaneous beating and ectopic stimulation. European Heart Journal, 13(4), 535-543.

17. Wyman, B. T., Hunter, W. C., Prinzen, F. W., \& McVeigh, E. R. (1999). Mapping propagation of mechanical activation in the paced heart with MRI tagging. American Journal of Physiology, 276(3 Pt 2), H881-H891.

18. Russell, K., Opdahl, A., Remme, E. W., Gjesdal, O., Skulstad, H., Kongsgaard, E., Edvardsen, T., \& Smiseth, O. A. (2010). Evaluation of left ventricular dyssynchrony by onset of active myocardial force generation: a novel method that differentiates between electrical and mechanical etiologies. Circulation. Cardiovascular Imaging, 3(4), 405-414. doi:10.1161/CIRCIMAGING.109.905539.

19. Russell K, Smiseth OA, Gjesdal O, Qvigstad E, Norseng PA, Sjaastad I, Opdahl A, Skulstad H, Edvardsen T, Remme EW (2011) Mechanism of prolonged electro-mechanical delay in late activated myocardium during left bundle branch block. Am J Physiol. doi:10.1152/ajpheart.00644.2011 
20. Parsai, C., Bijnens, B., Sutherland, G. R., Baltabaeva, A., Claus, P., Marciniak, M., Paul, V., Scheffer, M., Donal, E., Derumeaux, G., \& Anderson, L. (2009). Toward understanding response to cardiac resynchronization therapy: left ventricular dyssynchrony is only one of multiple mechanisms. European Heart Journal, 30 (8), 940-949. doi:10.1093/eurheartj/ehn481.

21. Baller, D., Wolpers, H. G., Zipfel, J., Bretschneider, H. J., \& Hellige, G. (1988). Comparison of the effects of right atrial, right ventricular apex and atrioventricular sequential pacing on myocardial oxygen consumption and cardiac efficiency: a laboratory investigation. Pacing and Clinical Electrophysiology, 11(4), 394-403.

22. Prinzen, F. W., Augustijn, C. H., Arts, T., Allessie, M. A., \& Reneman, R. S. (1990). Redistribution of myocardial fiber strain and blood flow by asynchronous activation. American Journal of Physiology, 259(2 Pt 2), H300-H308.

23. Breithardt, O. A., Stellbrink, C., Herbots, L., Claus, P., Sinha, A. M., Bijnens, B., Hanrath, P., \& Sutherland, G. R. (2003). Cardiac resynchronization therapy can reverse abnormal myocardial strain distribution in patients with heart failure and left bundle branch block. Journal of the American College of Cardiology, 42(3), 486-494.

24. Prinzen, F. W., Hunter, W. C., Wyman, B. T., \& McVeigh, E. R. (1999). Mapping of regional myocardial strain and work during ventricular pacing: experimental study using magnetic resonance imaging tagging. Journal of the American College of Cardiology, 33(6), 1735-1742.

25. van Oosterhout, M. F., Prinzen, F. W., Arts, T., Schreuder, J. J., Vanagt, W. Y., Cleutjens, J. P., \& Reneman, R. S. (1998). Asynchronous electrical activation induces asymmetrical hypertrophy of the left ventricular wall. Circulation, 98(6), 588-595.

26. van Oosterhout, M. F., Arts, T., Muijtjens, A. M., Reneman, R. S., \& Prinzen, F. W. (2001). Remodeling by ventricular pacing in hypertrophying dog hearts. Cardiovascular Research, 49(4), 771-778.

27. Prinzen, F. W., \& Bassingthwaighte, J. B. (2000). Blood flow distributions by microsphere deposition methods. Cardiovascular Research, 45(1), 13-21.

28. van Oosterhout, M. F., Arts, T., Bassingthwaighte, J. B., Reneman, R. S., \& Prinzen, F. W. (2002). Relation between local myocardial growth and blood flow during chronic ventricular pacing. Cardiovascular Research, 53(4), 831-840.

29. Matzer, L., Kiat, H., Friedman, J. D., Van Train, K., Maddahi, J., \& Berman, D. S. (1991). A new approach to the assessment of tomographic thallium-201 scintigraphy in patients with left bundle branch block. Journal of the American College of Cardiology, 17 (6), 1309-1317.

30. Hayat, S. A., Dwivedi, G., Jacobsen, A., Lim, T. K., Kinsey, C., \& Senior, R. (2008). Effects of left bundle-branch block on cardiac structure, function, perfusion, and perfusion reserve: implications for myocardial contrast echocardiography versus radionuclide perfusion imaging for the detection of coronary artery disease. Circulation, 117 (14), 1832-1841. doi:10.1161/CIRCULATIONAHA.107.726711.

31. Ono, S., Nohara, R., Kambara, H., Okuda, K., \& Kawai, C. (1992). Regional myocardial perfusion and glucose metabolism in experimental left bundle branch block. Circulation, 85 (3), 1125-1131

32. Altehoefer, C., Vom Dahl, J., Bares, R., Stocklin, G. L., \& Bull, U. (1995). Metabolic mismatch of septal beta-oxidation and glucose utilization in left bundle branch block assessed with PET. Journal of Nuclear Medicine: official publication, Society of Nuclear Medicine, 36(11), 2056-2059.

33. Zanco, P., Desideri, A., Mobilia, G., Cargnel, S., Milan, E., Celegon, L., Buchberger, R., \& Ferlin, G. (2000). Effects of left bundle branch block on myocardial FDG PET in patients without significant coronary artery stenoses. Journal of Nuclear Medicine: official publication, Society of Nuclear Medicine, 41(6), 973-977.

34. Masci, P. G., Marinelli, M., Piacenti, M., Lorenzoni, V., Positano, V., Lombardi, M., L'Abbate, A., \& Neglia, D. (2010). Myocardial structural, perfusion, and metabolic correlates of left bundle branch block mechanical derangement in patients with dilated cardiomyopathy: a tagged cardiac magnetic resonance and positron emission tomography study. Circulation. Cardiovascular Imaging, 3(4), 482-490. doi:10.1161/CIRCIMAGING.109.934638.

35. Vernooy, K., Cornelussen, R. N., Verbeek, X. A., Vanagt, W. Y., van Hunnik, A., Kuiper, M., Arts, T., Crijns, H. J., \& Prinzen, F. W. (2007). Cardiac resynchronization therapy cures dyssynchronopathy in canine left bundle-branch block hearts. European Heart Journal, 28(17), 2148-2155. doi:10.1093/eurheartj/ehm207.

36. Wyman, B. T., Hunter, W. C., Prinzen, F. W., Faris, O. P., \& McVeigh, E. R. (2002). Effects of single- and biventricular pacing on temporal and spatial dynamics of ventricular contraction. American Journal of Physiology-Heart and Circulatory Physiology, 282(1), H372-H379.

37. Vernooy, K., Verbeek, X. A., Peschar, M., Crijns, H. J., Arts, T., Cornelussen, R. N., \& Prinzen, F. W. (2005). Left bundle branch block induces ventricular remodelling and functional septal hypoperfusion. European Heart Journal, 26(1), 91-98. doi:10.1093/ eurheartj/ehi008.

38. Prinzen, F. W., Cheriex, E. C., Delhaas, T., van Oosterhout, M. F., Arts, T., Wellens, H. J., \& Reneman, R. S. (1995). Asymmetric thickness of the left ventricular wall resulting from asynchronous electric activation: a study in dogs with ventricular pacing and in patients with left bundle branch block. American Heart Journal, 130(5), 1045-1053.

39. Strik, M., Ploux, S., Vernooy, K., \& Prinzen, F. W. (2011). Cardiac resynchronization therapy: refocus on the electrical substrate. Circulation Journal, 75(6), 1297-1304.

40. Linde, C., Abraham, W. T., Gold, M. R., St John Sutton, M., Ghio, S., \& Daubert, C. (2008). Randomized trial of cardiac resynchronization in mildly symptomatic heart failure patients and in asymptomatic patients with left ventricular dysfunction and previous heart failure symptoms. Journal of the American College of Cardiology, 52(23), 1834-1843. doi:10.1016/j.jacc.2008.08.027.

41. Tang, A. S., Wells, G. A., Talajic, M., Arnold, M. O., Sheldon, R., Connolly, S., Hohnloser, S. H., Nichol, G., Birnie, D. H., Sapp, J. L., Yee, R., Healey, J. S., \& Rouleau, J. L. (2010). Cardiacresynchronization therapy for mild-to-moderate heart failure. The New England Journal of Medicine. doi:10.1056/NEJMoa1009540.

42. Solomon, S. D., Foster, E., Bourgoun, M., Shah, A., Viloria, E., Brown, M. W., Hall, W. J., Pfeffer, M. A., \& Moss, A. J. (2010). Effect of cardiac resynchronization therapy on reverse remodeling and relation to outcome: multicenter automatic defibrillator implantation trial: cardiac resynchronization therapy. Circulation, 122(10), 985-992. doi:10.1161/CIRCULATIONAHA.110.955039.

43. van Geldorp, I. E., Vernooy, K., Delhaas, T., Prins, M. H., Crijns, H. J., Prinzen, F. W., \& Dijkman, B. (2010). Beneficial effects of biventricular pacing in chronically right ventricular paced patients with mild cardiomyopathy. Europace, 12(2), 223-229. doi:10.1093/europace/eup378.

44. Rademakers, L. M., van Kerckhoven, R., van Deursen, C. J., Strik, M., van Hunnik, A., Kuiper, M., Lampert, A., Klersy, C., Leyva, F., Auricchio, A., Maessen, J. G., \& Prinzen, F. W. (2010). Myocardial infarction does not preclude electrical and hemodynamic benefits of cardiac resynchronization therapy in dyssynchronous canine hearts. Circulation. Arrhythmia and Electrophysiology, 3 (4), 361-368. doi:10.1161/CIRCEP.109.931865.

45. van Deursen, C., van Geldorp, I. E., Rademakers, L. M., van Hunnik, A., Kuiper, M., Klersy, C., Auricchio, A., \& Prinzen, F. W. (2009). Left ventricular endocardial pacing improves resynchronization therapy in canine left bundle-branch hearts. Circulation. Arrhythmia and Electrophysiology, 2(5), 580-587. doi:10.1161/ CIRCEP.108.846022.

46. Derval, N., Steendijk, P., Gula, L. J., Deplagne, A., Laborderie, J., Sacher, F., Knecht, S., Wright, M., Nault, I., Ploux, S., Ritter, P., 
Bordachar, P., Lafitte, S., Reant, P., Klein, G. J., Narayan, S. M., Garrigue, S., Hocini, M., Haissaguerre, M., Clementy, J., \& Jais, P. (2010). Optimizing hemodynamics in heart failure patients by systematic screening of left ventricular pacing sites: the lateral left ventricular wall and the coronary sinus are rarely the best sites. Journal of the American College of Cardiology, 55(6), 566-575. doi:10.1016/j.jacc.2009.08.045.

47. Spragg, D. D., Dong, J., Fetics, B. J., Helm, R., Marine, J. E., Cheng, A., Henrikson, C. A., Kass, D. A., \& Berger, R. D. (2010). Optimal left ventricular endocardial pacing sites for cardiac resynchronization therapy in patients with ischemic cardiomyopathy. Journal of the American College of Cardiology, 56(10), 774781. doi:10.1016/j.jacc.2010.06.014.

48. Ginks, M. R., Lambiase, P. D., Duckett, S. G., Bostock, J., Chinchapatnam, P., Rhode, K., McPhail, M. J., Simon, M., Bucknall, C., Carr-White, G., Razavi, R., \& Rinaldi, C. A. (2011). A simultaneous $\mathrm{X}-\mathrm{MRI}$ and non contact mapping study of the acute hemodynamic effect of left ventricular endocardial and epicardial cardiac resynchronization therapy in humans. Circulation. Heart Failure, 4(2), 170-179. doi:10.1161/CIRCHEARTFAILURE.110.958124.

49. Strik, M., Rademakers, L. M., van Deursen, C. J., van Hunnik, A., Kuiper, M., Klersy, C., Auricchio, A., \& Prinzen, F. W. (2011). Endocardial left ventricular pacing improves cardiac resynchronization therapy in chronic asynchronous infarction and heart failure models. Circulation. Arrhythmia and Electrophysiology. doi:10.1161/CIRCEP.111.965814.

50. Helm, R. H., Byrne, M., Helm, P. A., Daya, S. K., Osman, N. F., Tunin, R., Halperin, H. R., Berger, R. D., Kass, D. A., \& Lardo, A. C. (2007). Three-dimensional mapping of optimal left ventricular pacing site for cardiac resynchronization. Circulation, 115(8), 953-961. doi:10.1161/CIRCULATIONAHA.106.643718.

51. Prabhu, S. D., \& Freeman, G. L. (1995). Effect of tachycardia heart failure on the restitution of left ventricular function in closed-chest dogs. Circulation, 91(1), 176-185.

52. Bogaard, M. D., Houthuizen, P., Bracke, F. A., Doevendans, P. A., Prinzen, F. W., Meine, M., \& van Gelder, B. M. (2011). Baseline left ventricular $\mathrm{dP} / \mathrm{dtmax}$ rather than the acute improvement in $\mathrm{dP} /$ dtmax predicts clinical outcome in patients with cardiac resynchronization therapy. European Journal of Heart Failure, 13(10), 1126-1132. doi:10.1093/eurjhf/hfr094.

53. Barth, A. S., Aiba, T., Halperin, V., DiSilvestre, D., Chakir, K., Colantuoni, C., Tunin, R. S., Dimaano, V. L., Yu, W., Abraham, T. P., Kass, D. A., \& Tomaselli, G. F. (2009). Cardiac resynchronization therapy corrects dyssynchrony-induced regional gene expression changes on a genomic level. Circulation. Cardiovascular Genetics, 2(4), 371-378. doi:10.1161/CIRCGENETICS.108.832345.

54. Aiba, T., Hesketh, G. G., Barth, A. S., Liu, T., Daya, S., Chakir, K., Dimaano, V. L., Abraham, T. P., O'Rourke, B., Akar, F. G., Kass, D. A., \& Tomaselli, G. F. (2009). Electrophysiological consequences of dyssynchronous heart failure and its restoration by resynchronization therapy. Circulation, 119(9), 1220-1230. doi:10.1161/ CIRCULATIONAHA.108.794834.

55. Chakir, K., Daya, S. K., Aiba, T., Tunin, R. S., Dimaano, V. L., Abraham, T. P., Jaques-Robinson, K. M., Lai, E. W., Pacak, K., Zhu, W. Z., Xiao, R. P., Tomaselli, G. F., \& Kass, D. A. (2009). Mechanisms of enhanced beta-adrenergic reserve from cardiac resynchronization therapy. Circulation, 119(9), 1231-1240. doi:10.1161/CIRCULATIONAHA.108.774752.

56. Verheule, S., Wilson, E., Tt, E., Shanbhag, S., Golden, C., \& Olgin, J. (2003). Alterations in atrial electrophysiology and tissue structure in a canine model of chronic atrial dilatation due to mitral regurgitation. Circulation, 107(20), 2615-2622. doi:10.1161/01. CIR.0000066915.15187.51.

57. Mills, R. W., Cornelussen, R. N., Mulligan, L. J., Strik, M., Rademakers, L. M., Skadsberg, N. D., van Hunnik, A., Kuiper, M., Lampert, A., Delhaas, T., \& Prinzen, F. W. (2009). Left ventricular septal and left ventricular apical pacing chronically maintain cardiac contractile coordination, pump function and efficiency. Circulation. Arrhythmia and Electrophysiology, 2 (5), 571-579. doi:10.1161/CIRCEP.109.882910.

58. Hori, Y., Tsubaki, M., Katou, A., Ono, Y., Yonezawa, T., Li, X., \& Higuchi, S. I. (2008). Evaluation of NT-pro BNP and CT-ANP as markers of concentric hypertrophy in dogs with a model of compensated aortic stenosis. Journal of Veterinary Internal Medicine, 22(5), 1118-1123. doi:10.1111/j.1939-1676.2008.0161.x.

59. Mathieu, M., El Oumeiri, B., Touihri, K., Hadad, I., Mahmoudabady, M., Thoma, P., Metens, T., Bartunek, J., Heyndrickx, G. R., Brimioulle, S., Naeije, R., \& Mc Entee, K. (2010). Ventricular-arterial uncoupling in heart failure with preserved ejection fraction after myocardial infarction in dogs - invasive versus echocardiographic evaluation. BMC Cardiovascular Disorders, 10, 32. doi:10.1186/ 1471-2261-10-32.

60. Urabe, Y., Mann, D. L., Kent, R. L., Nakano, K., Tomanek, R. J., Carabello, B. A., \& Gt, C. (1992). Cellular and ventricular contractile dysfunction in experimental canine mitral regurgitation. Circulation Research, 70(1), 131-147. 